\title{
A razão pode ser instrumento de inclusão da loucura? Olhares sobre a medida de segurança
}

\author{
Can reason be a tool for including madness? Views on the security \\ measure
}

Ariadne Villela Lopes ${ }^{\mathbf{1}}$, Gabriel Eduardo Schutz ${ }^{\mathbf{2}}$

DOI: 10.1590/0103-11042019S417

RESUMO Este ensaio discute, no ponto de vista dos direitos humanos e com base na Teoria Geral do Crime adotada pelo Código Penal Brasileiro, o caso de indivíduos declarados inimputáveis por doença mental que praticam fato tipificado como crime típico e ilícito. Apresentam-se os conceitos jurídicos necessários para compreender o procedimento judicial apropriado para a declaração de inimputabilidade de um réu em ação criminal, especificando as consequências legais de tal declaração, isto é, a imposição de uma medida de segurança. Avalia-se a possibilidade de que, na prática de fatos tipificados como delitos pelos sujeitos inimputáveis psíquicos, haja utilização de outros recursos extrapenais, que atendam aos princípios do movimento antimanicomial, positivados na Lei $n^{\circ} 10.216 / 2001$, no sentido de garantir a proteção dos direitos das pessoas portadoras de transtornos mentais, contrapondo-se ao estabelecido no Código Penal.

PALAVRAS-CHAVE Transtornos mentais. Medidas de segurança. Direitos humanos.

\begin{abstract}
This essay discusses, from the point of view of Human Rights and based on the General Theory of Crime adopted by the Brazilian Penal Code, the case of individuals declared inimputable for mental illness who practice a typified fact as a typical and illicit crime. The legal concepts required to understand the appropriate judicial procedure for the declaration of inimputability of a defendant in criminal action are presented, specifying the legal consequences of such declaration, that is, the imposition of a security measure. It also assess the possibility of, in the practice of facts typified as crimes by inimputable subjects, using other extra-criminal resources, which meet the principles of the Anti-Asylum movement, affirmed by Law $n^{\circ} .10 .216 / 2001$, in order to guarantee the protection of rights of persons with mental disorders, as opposed to the Penal Code.
\end{abstract}

KEYWORDS Mental disorders. Security measures. Human rights.

\footnotetext{
1 Tribunal de Justiça do
Estado do Rio de Janeiro

1 Tribunal de Justiça do
Estado do Rio de Janeiro (TJRJ) - Rio de Janeiro (RJ), Brasil.

dinevlopes@gmail.com 2 Universidade Federal do

Rio de Janeiro (UFRJ) - Rio
de Janeiro (RJ), Brasil.

Rio de Janeiro (UFRJ) - Rio
de Janeiro (RJ), Brasil.
} 


\section{Introdução}

O ponto de partida da análise aqui apresentada é a percepção do anacronismo das disposições do Código Penal Brasileiro ${ }^{1}$ relativas à imposição de medida de segurança a indivíduos declarados portadores de transtornos mentais por perícia médico-psiquiátrica, no curso de inquérito policial ou de processo criminal que apuram a prática de fato típico e ilícito, cuja autoria é atribuída a tais indivíduos. Tais agentes, segundo a nomenclatura penal, são nominados inimputáveis, e a consequência da declaração dessa condição é o reconhecimento de sua incapacidade de entender o caráter ilícito do fato por eles praticado ou de se autodeterminar de acordo com esse entendimento.

As disposições relativas à medida de segurança figuram nos arts. 96 a 99 do Código Penal', compondo seu Título VI da Parte Geral, o que implica sua potencial imposição para indivíduos praticantes de qualquer tipo penal, esteja este previsto no próprio Código Penal ${ }^{1}$ ou em lei penal extravagante, visto que a Parte Geral do Código Penal1, como o próprio nome indica, tem ampla aplicação na seara criminal, não se restringindo sua imposição a sujeitos praticantes de delitos tipificados no referido código.

Questiona-se, portanto, a possibilidade de utilização de outros recursos extrapenais como consequência da prática de fatos tipificados como delitos pelos sujeitos inimputáveis psíquicos. Nesse contexto, em análise da Lei ${ }^{\circ}$ $10.216 / 2001^{2}$, verificou-se que esta dispõe sobre a proteção e os direitos das pessoas portadoras de transtornos mentais, bem como estabelece modelo de cuidado e assistência a tais pessoas diverso do estabelecido no Código Penal.

Diante de tal dicotomia de tratamento legal, surgiram os seguintes questionamentos: em conformidade com a legislação brasileira, há possibilidade de não se aplicar medida de segurança ao inimputável por doença mental que pratica fato típico e ilícito? Qual norma legal, entre as duas apontadas como potencialmente aplicáveis, vem sendo efetivamente utilizada no contexto da prática de fato típico e ilícito por sujeito inimputável por doença mental?

A seguir, será apresentada uma série de definições e argumentações necessárias à uma análise de critérios de interpretação jurídica, cuja aplicação traz segurança jurídica e reduz margem de discussão acerca de eventual alegação de ativismo judicial, que recebe críticas de parte da comunidade jurídica sob o fundamento de representar interferência indevida do Poder Judiciário nos demais poderes da República Brasileira.

Parte-se da exposição da Teoria Geral do Crime adotada pelo Código Penal Brasileiro 1 , apresentando-se os elementos formadores do delito, com os respectivos conceitos. A exposição e a análise dos elementos do crime limitam-se ao objeto de interesse do estudo, que é o sujeito inimputável por doença mental que pratica fato tipificado como crime, mostrando-se típico e ilícito. Na sequência, se discutirá o procedimento judicial necessário e adequado à declaração de inimputabilidade de indivíduo que se encontra na condição de réu em ação penal, com especificação da consequência jurídica de tal declaração: imposição de medida de segurança.

Uma análise das características da medida de segurança, com problematização das disposições legais que a preveem, permite indagar acerca do futuro do doente mental praticante de fato típico e ilícito, com apresentação e análise das disposições da Lei ${ }^{0} 10.216 / 2001^{2}$, que dispõe sobre a proteção e os direitos das pessoas portadoras de transtornos mentais e redireciona o modelo assistencial em saúde mental. Nesse sentido, aponta-se nova perspectiva acerca da consequência jurídica da prática de fato típico e ilícito por doente mental, mesmo em um contexto de retrocessos políticos do paradigma antimanicomial.

\section{Os conceitos fundamentais}

Para esta análise, é adotado o conceito tripartido de crime, uma vez que se mostra mais adequado às previsões do Código Penal', que projeta o delito composto por três elementos: fato típico, ilicitude e culpabilidade. 
Outrossim, interessa caracterizar a tipicidade penal, a qual é o resultado da análise objetiva realizada pelo operador do direito, que aponta para a presença da tipicidade formal e da tipicidade material.

A tipicidade formal ocorre quando se verifica a perfeita adequação da conduta praticada pelo agente ao tipo penal previsto em lei. Verifica-se a perfeita adequação quando todos os elementos descritivos contidos no tipo penal foram contemplados na conduta do agente. Nesse sentido, o tipo penal deve descrever a conduta delituosa e, portanto, proibida pelo ordenamento jurídico, de forma integral, para que o intérprete (seja ele o cidadão sujeito à norma jurídico-penal, seja o técnico operador do direito) dela tenha conhecimento e possa escolher os comportamentos que decide adotar: sejam eles contrários ou não à norma penal.

Por seu turno, fala-se em tipicidade material quando a conduta, que se amolda perfeitamente ao tipo penal, efetivamente lesiona bem jurídico tutelado pela norma penal. Para que haja tipicidade material, é necessário, portanto, que haja efetiva lesão ao bem jurídico tutelado pela norma. Em regra, conduta formalmente típica gera lesão a bem jurídico penalmente tutelado, afirmativa esta que se mostra compatível com a Teoria Geral do Delito atualmente majoritária. Contudo, por construção da doutrina jurídica e da jurisprudência, foram criadas algumas hipóteses em que, apesar de haver a perfeita adequação do fato praticado pelo agente à descrição típica prevista na lei penal, tal fato não é típico por não gerar efetiva lesão ao bem jurídico tutelado, afastando, assim, a caracterização do crime.

Passa-se, em seguida, à contextualização, composição e conceituação de cada um dos três elementos constitutivos do crime, segundo a dogmática jurídica atualmente majoritária no Brasil.

\section{Fato típico}

Além da tipicidade, o fato típico é composto por: conduta humana, resultado, relação de causalidade entre conduta e resultado (quando cabível).

\section{Conduta humana}

Para que uma conduta seja caracterizada como crime, ela deve ser praticada por pessoa humana, ainda, para ter relevância penal, a conduta humana deve ser consciente e voluntária, sendo os atos inconscientes e involuntários irrelevantes penais.

Em relação à finalidade da conduta humana consciente e voluntária, ou seja, em relação ao fim ao qual ela se dirige, o Código Penal Brasileiro ${ }^{1}$ adotou, após a reforma legislativa introduzida pela Lei $n^{0} 7.209$, de 11 de julho de 1984, a Teoria Finalista da Ação3. Segundo tal teoria, toda ação humana tem um objetivo específico, e o ser humano age para atingir tal objetivo. Quando o fim visado é contrário ao direito e a conduta se amolda a um tipo penal, ou seja, à descrição de conduta descrita na lei penal, diz-se que o fato é típico, já que a conduta é dolosa (dotada de intenção de atingir o resultado que infringe a norma penal).

São relevantes penais, portanto, apenas as condutas humanas conscientes e voluntárias, dirigidas a uma finalidade específica (condutas dolosas) ou executadas com imprudência, negligência ou imperícia (condutas humanas culposas).

Ainda no que tange à conduta humana, esta pode se exteriorizar de duas maneiras: mediante ação ou por meio de omissão. Nesse sentido, fala-se em condutas comissivas e omissivas respectivamente.

As condutas comissivas são as praticadas de forma positiva, ou seja, são um fazer humano, ocorrendo quando a pessoa interfere no mundo dos fatos de forma ativa, podendo ou não gerar resultado concreto. As condutas humanas comissivas interessam ao direito penal quando violam normas penais proibitivas.

Por sua vez, as condutas omissivas são as praticadas de forma negativa, são um não fazer, um abster-se de atuar quando o ordenamento jurídico exige do sujeito uma atuação positiva. Da redação do artigo $13, \subseteq 2^{\circ}$, do Código Penal', verifica-se que, para que a omissão seja penalmente relevante nos delitos comissivos por 
omissão, é necessário que o sujeito possa agir para impedir o resultado, visto que não se exige conduta heroica para que se impeça o resultado.

\section{Resultado}

O resultado é a consequência da conduta praticada pelo sujeito, e, conforme Manson ${ }^{3}$, pode ter duas espécies:

Em direito penal, o resultado pode ser jurídico ou naturalístico. 'Resultado jurídico', ou normativo, é a lesão ou exposição a perigo de lesão do bem jurídico protegido pela lei penal. É, simplesmente, a violação da lei penal, mediante a agressão do valor ou interesse por ela tutelado. 'Resultado naturalístico', ou 'material', é a modificação do mundo exterior provocada pela conduta do agente ${ }^{3(256)}$.

Bens jurídicos são os valores apontados pelo legislador penal como merecedores de tutela. Eles variam de acordo com a cultura dos povos e o momento histórico. No atual sistema jurídico penal brasileiro, tem-se, exemplificativamente, a tutela: da vida (sendo criminalizados, porque violadores de tal bem jurídico, o homicídio; o induzimento, a instigação e o auxílio ao suicídio e o aborto); do patrimônio (criminalizando, por exemplo, o furto, o roubo e a extorsão); e da dignidade sexual (cuja tutela conduz à criminalização do estupro e do estupro de vulnerável). Por outro lado, o delito de adultério, que, supostamente, tutelava a família e o casamento, deixou de existir em nosso ordenamento jurídico em 2005.

Assim, todo crime causa lesão ao bem jurídico tutelado pela norma penal contida no tipo penal respectivo. Conforme referido, a prática do homicídio, quer seja tentado ou consumado, gera lesão ao bem jurídico tutelado - vida -, mesmo que, na hipótese de tentativa sem lesão física efetiva (quando os tiros, por exemplo, não atingem a vítima), o bem jurídico restou violado.

\section{Relação de causalidade entre condu- ta e resultado ou nexo causal}

Relação de causalidade é o vínculo efetivo entre a conduta do agente e o resultado produzido no mundo real. É a ponte imaginária que liga a conduta ao resultado visível no mundo real. Por meio da relação de causalidade, é possível vincular o agente ao resultado decorrente de sua conduta e imputar-lhe o resultado concreto produzido. Portanto, só é cabível falar em relação de causalidade nos crimes materiais, visto que, em delitos de mera conduta e formais, ou não há resultado, ou este é dispensado para a consumação do crime respectivamente.

Ao se estabelecer a relação de causalidade, está-se, simultaneamente, estabelecendo a imputação do resultado obtido ao agente, em razão da conduta praticada por este, que se amolda a um tipo penal, ou seja, a uma descrição de ação ou omissão estabelecida em lei.

\section{Ilicitude}

Ilicitude significa contrariedade à ordem jurídica. Especificamente no âmbito do direito penal, significa a contrariedade do fato típico praticado pelo indivíduo à norma jurídico-penal, sendo apto tal fato típico a causar lesão a um bem jurídico tutelado pela norma penal.

As causas excludentes de ilicitude do fato típico são classificadas em causas legais e supralegais; causas gerais ou genéricas e causas específicas ou especiais, sendo as gerais ou genéricas aplicáveis a quaisquer crimes, e as específicas ou especiais aplicáveis somente a delitos específicos, conforme leciona Masson ${ }^{3}$.

Nesta análise, é conveniente limitar a abordagem às expressamente previstas em lei e gerais ou genéricas, as quais estão enunciadas no art. 23 do Código Penal'1, que assim dispõe:

Exclusão de ilicitude

Art. 23. Não há crime quando o agente pratica o fato:

I - em estado de necessidade;

II - em legítima defesa; 
III - em estrito cumprimento de dever legal ou no exercício regular de direito.

Excesso punível

Parágrafo único. O agente, em qualquer das hipóteses deste artigo, responderá pelo excesso doloso ou culposo'.

\section{Culpabilidade}

A culpabilidade, conforme já referido, é o terceiro elemento do conceito analítico de crime. Presentes os elementos anteriores (fato típico e ilicitude), passa-se à análise da culpabilidade do agente.

Ao longo do tempo, juristas criaram diversas teorias para explicar tal elemento do crime. Contudo, considerando o objetivo deste trabalho, não será apresentada a linha evolutiva de tais teorias em razão de que a sua exposição extrapola tal objetivo. Ademais, é mister que o leitor conheça a teoria atualmente aplicada em nosso Código Penal', não se mostrando útil digressão acerca de entendimentos que não são aplicáveis atualmente no Brasil.

Segundo a Teoria Limitada da Culpabilidade, esta "se transforma em um simples juízo de reprovabilidade que incide sobre o autor de um fato típico e ilícito"3(500), possuindo a culpabilidade três elementos constitutivos, que devem ser analisados nesta ordem: 1) imputabilidade do agente; 2) potencial consciência da ilicitude da conduta praticada pelo sujeito; 3) exigibilidade de conduta diversa. De acordo com Masson', os elementos constitutivos da culpabilidade ordenam-se hierarquicamente, de tal modo que o segundo pressupõe o primeiro; e o terceiro, os dois anteriores. De fato, se o indivíduo é inimputável, não pode ter a potencial consciência da ilicitude. De modo semelhante, se não tem a consciência potencial da ilicitude, não lhe pode ser exigível conduta diversa. Logo, para que seja possível ao sujeito compreender o caráter ilícito do fato por ele praticado, mesmo que de forma potencial, e se determinar em conformidade com tal entendimento, necessariamente ele deve ser imputável.

Contudo, uma vez que este estudo visa à proposição de alternativas à aplicação da medida de segurança ao inimputável por doença mental que pratica fato típico e ilícito, conclui-se que a avaliação dos elementos da potencial consciência da ilicitude do fato e da exigibilidade de conduta diversa tornam-se desinteressantes no caso. Tal conclusão decorre do fato de que, por ser inimputável, do doente mental, não pode ser exigida potencial consciência da ilicitude do fato por ele praticado, tampouco conduta diversa. Logo, a aferição dos elementos da culpabilidade deve ser interrompida, tão logo o primeiro deles não se mostrar presente, ou seja, quando o sujeito praticante de fato típico e ilícito for, comprovadamente, inimputável, mais especificamente, inimputável por doença mental. Assim, cabe agora abordar o conceito de imputabilidade.

Isto é relevante, pois enquanto os dois primeiros elementos do crime (fato típico e ilicitude) são apurados em relação ao próprio fato praticado pelo sujeito, a culpabilidade, conforme referido, é juízo de reprovabilidade que recai sobre a formação e manifestação da vontade desse mesmo sujeito. Assim, a culpabilidade não está relacionada com o fato, mas com as circunstâncias do sujeito praticante de fato típico e ilícito, possuindo, portanto, matriz subjetiva e personalíssima.

Nesse contexto, a aferição da imputabilidade do sujeito possui grande importância, pois é imanente à sua subjetividade e às suas condições pessoais.

O Código Penal Brasileiro ${ }^{1}$ não conceitua imputabilidade penal. Limita-se a estabelecer os casos de inimputabilidade e a elucidar hipóteses duvidosas. Logo, a lei presume a imputabilidade do agente, quando ausentes as hipóteses de inimputabilidade.

A lei penal brasileira presume, de forma relativa, a imputabilidade do sujeito maior 
de 18 anos, pois admite prova em contrário. Para a aferição da imputabilidade do maior de 18 anos, o Código Penal adotou o critério biopsicológico.

Conforme explica Masson³, segundo tal critério:

É inimputável quem, ao tempo da conduta, apresenta um problema mental, e, em razão disso, não possui capacidade para entender o caráter ilícito do fato ou determinar-se de acordo com esse entendimento. Esse sistema conjuga as atuações do magistrado e do perito. Este (perito) trata da questão biológica, aquele (juiz) da psicológica. A presunção de imputabilidade é relativa (iuris tantum): após os 18 anos, todos são imputáveis, salvo prova pericial em sentido contrário revelando a presença de causa mental deficiente, bem como o reconhecimento de que, por tal motivo, o agente não tinha ao tempo da conduta capacidade para entender o caráter ilícito do fato ou de determinar-se de acordo com esse entendimento3(511).

Mais uma vez, com foco no desiderato do presente trabalho, será analisada somente a hipótese do art. 26, caput, do Código Penal', que estabelece a inimputabilidade do doente mental, que, comprovadamente, era inteiramente incapaz de entender o caráter ilícito do fato por ele praticado, inviabilizando, assim, sua autodeterminação acerca da prática ou não do respectivo fato.

Assim, a doença mental (da qual o sujeito encontrava-se comprovadamente acometido quando da prática da conduta típica e ilícita) é excludente da imputabilidade e, consequentemente, da culpabilidade, que é juízo de reprovação sobre a formação e exteriorização da vontade do sujeito. Sendo negativo tal juízo de reprovação, verifica-se a exclusão da culpabilidade, que se constitui no terceiro elemento do conceito analítico de crime, restando excluído, igualmente, o crime. Por conseguinte, a ausência de crime impede a aplicação de pena ao sujeito.

\section{O procedimento de apuração de inimputabilidade e suas consequências jurídicas}

O procedimento apontado na legislação processual penal para aferição da inimputabilidade psíquica do réu é o Incidente de Insanidade Mental, previsto nos arts. 149 a 154 do Código de Processo Penal'.

\section{Incidente de Insanidade Mental}

O objetivo da instauração do Incidente de Insanidade Mental do acusado é a realização de exame pericial, com elaboração de laudo médico-psiquiátrico (elaborado por médico psiquiatra), para constatação de sua sanidade ou insanidade mental. O art. 149 ${ }^{1}$, caput, aduz 'exame médico-legal' para indicar o exame pericial e o laudo médico correspondente.

É incidente procedimental, porque é instaurado durante a fase de inquérito policial ou durante o curso de processo criminal, cujo objetivo é instrumentalizar o processo principal, uma vez que é deflagrado para apurar eventual irresponsabilidade penal do sujeito que, supostamente, praticou fato típico e ilícito.

O art. 149 do Código de Processo Penal ${ }^{1}$ prevê que, quando houver dúvida sobre a integridade mental do acusado, o juiz ordenará, de ofício ou a requerimento do Ministério Público, do defensor, do curador, do ascendente, descendente, irmão ou cônjuge do acusado, que seja este submetido a exame médico-legal.

Tal dispositivo legal estabelece quem são os sujeitos legitimados processualmente para requerer a instauração do Incidente de Insanidade Mental:

a) autoridade policial, que preside o inquérito policial;

b) Ministério Público, órgão acusador no processo criminal; 
c) defensor, seja público ou particular (advogado constituído);

d) curador do réu. A curatela, no direito civil, é

o encargo imposto a uma pessoa natural para cuidar e proteger uma pessoa maior de idade que não pode se autodeterminar patrimonialmente por conta de uma incapacidade(906);

e) parentes do periciado (indiciado ou acusado): ascendentes, descendentes, irmão ou cônjuge.

A autoridade competente para determinar a instauração do Incidente de Insanidade Mental é a autoridade judiciária, estritamente, ou seja, o juiz criminal que preside o processo judicial no qual se dá a respectiva instauração ou em face do qual será o processo ajuizado, em conformidade com as regras de competência abstrata e previamente estabelecidas em lei (quando determinada a instauração do Incidente de Insanidade Mental na fase do inquérito policial), sob pena de violação ao Princípio do Juiz Natural, também figurante no rol dos direitos fundamentais previsto no art. $5^{0}$ da Constituição Federal ${ }^{5}$. A instauração do incidente pode, também, ser determinada de ofício pelo juiz, ou seja, independentemente de pedido de qualquer dos legitimados, conforme texto legal expresso do art. 149, caput, do Código de Processo Penal1.

Assim, além de aferida a doença mental do sujeito ao tempo da prática da conduta típica e ilícita - mediante exame médico-pericial -, para que ele seja considerado inimputável, é imprescindível que reste comprovada, também, sua total incapacidade de, ao tempo da conduta, entender o caráter ilícito desta e de determinar-se em conformidade com tal entendimento.

Atestada a doença mental por perito psiquiatra e concluindo o juiz, com base nas provas dos autos, que o sujeito se encontrava, ao tempo da conduta, incapacitado de entender o caráter ilícito do fato e de se autodeterminar de acordo com tal entendimento, será ele considerado inimputável e, consequentemente, terá afastada sua culpabilidade, não podendo ser declarado responsável pelo fato típico e ilícito por ele praticado. Logicamente, não sendo ele culpável, não poderá ter-lhe aplicada pena, visto que não configurado crime.

Em que pese o Código de Processo Penal ${ }^{1}$ estabelecer absolvição do réu em tal caso, qual seja, absolvição decorrente do reconhecimento da excludente de culpabilidade da inimputabilidade, essa absolvição é sui generis, conforme ressalta Carvalho ${ }^{6}$, chamada pela doutrina jurídica de absolvição imprópria.

Retomando o conceito de culpabilidade exposto anteriormente, verifica-se que, em relação ao sujeito culpável, o direito penal aplica o sistema de responsabilidade criminal, culminando na aplicação de pena ao autor do fato. Contudo, caso ausente a culpabilidade por incidência de uma de suas excludentes, tal o caso de inimputabilidade por doença mental, o direito penal adota o sistema de periculosidade do autor de fato típico e ilícito, implicando aplicação de medida de segurança ao mencionado sujeito.

Em outras palavras, o sistema de periculosidade é ancorado no exame médico-legal (perícia médico-psiquiátrica) previsto na legislação processual penal, elaborado durante o processamento do Incidente de Insanidade Mental, cuja consequência jurídica, em caso de restar certificada a inimputabilidade do sujeito autor do injusto, é a imposição de medida de segurança, nos termos já expostos.

A consequência jurídica de aplicação de medida de segurança ao inimputável psíquico decorre de opção de política criminal, que poderia, caso assim decidissem os estudiosos do direito penal, legitimados pelo legislador penal, ter outros contornos, resultando em outras consequências jurídicas aplicáveis em tais casos, para tais sujeitos de direitos.

\section{Medida de segurança}

Conforme referido, segundo previsão do art. 386, parágrafo único, III, Código de Processo Penal', uma vez declarada a inimputabilidade 
do indivíduo, a ele será aplicada medida de segurança, de acordo com o que estabelece o Código Penal. Passe-se, então, à análise de tal consequência jurídico-legal da declaração de inimputabilidade do acusado.

As notas da prevenção e da periculosidade estão presentes no conceito adotado pela doutrina jurídica para a medida de segurança. Por todos, Masson(935).

Medida de segurança é modalidade de sanção penal com finalidade exclusivamente preventiva, e de caráter terapêutico, destinada a tratar inimputáveis e semi-imputáveis portadores de periculosidade, com o escopo de evitar a prática de futuras infrações penais.

Verifica-se, portanto, evidente caráter aflitivo na medida de segurança, autorizando que ela se caracterize como sanção penal, visto que a aplicação de tal consequência jurídica decorre de sentença absolutória imprópria, imposta pelo magistrado, submetendo o inimputável psíquico a internação em hospital de custódia e tratamento psiquiátrico ou a tratamento ambulatorial.

O presente estudo limita-se à análise e à discussão acerca da medida de segurança detentiva, executada mediante internação do sujeito em hospital de custódia e tratamento psiquiátrico, que se classifica como espécie de instituição total, caracterizada por impor condições asilares e de nivelamento e aniquilamento do eu, por meio da normalização de pessoas, conforme descreve Goffman ${ }^{5}$.

Uma fragilidade deste procedimento subjaze no exame pericial, o qual se fundamenta em juízo de prognose quanto a eventual futuro injusto que possa vir a ser praticado pelo periciado; sendo tal juízo de prognose negativo, será ele revelador de sua periculosidade. Por isso a afirmação de Carvalho ${ }^{6}$ acerca da adoção do sistema de periculosidade pela legislação penal brasileira em face do sujeito inimputável.

Santos tece a seguinte crítica ao sistema de periculosidade e seus consectários:
O problema começa com a falta de credibilidade do 'prognóstico' de periculosidade criminal: se a medida de segurança pressupõe 'prognóstico' de comportamento criminoso futuro, então inconfiáveis 'laudos psiquiátricos' produzem consequências sociais destruidoras, porque podem determinar 'internações perpétuas' de cidadãos em instituições de segregação psiquiátrica - em condições gerais ainda piores do que as condições desumanas de execução da pena criminal7(646). [grifo do autor].

Assim, considerando as características das instituições totais em que são cumpridas as medidas de segurança detentivas e as circunstâncias em que elaborados os laudos periciais, por meio dos quais afere-se a permanência ou a cessação da periculosidade do agente inimputável, este corre riscos de, efetivamente, permanecer submetido a sanção perpétua, considerando as regras legais aplicáveis.

Diante de tal cenário, a $1^{\text {a }}$ Turma do Supremo Tribunal Federal, por unanimidade, já se manifestou no sentido de que deve ser aplicado ao cumprimento da medida de segurança o mesmo prazo máximo fixado na legislação para o cumprimento da pena privativa de liberdade, previsto no art. 75 do Código Penal'1 qual seja, 30 anos.

A insegurança jurídica gerada por normas dessa natureza decorre do fato de que pode ser que um intérprete da lei entenda que 'fato indicativo de persistência de periculosidade' é a prática de fato típico e ilícito (previsto na lei penal como crime) e outro entenda que é apenas a violação de alguma regra de natureza civil ou administrativa, como estacionar em local proibido por exemplo.

Por fim, concluindo a análise das regras dispostas no Código Penal ${ }^{1}$ acerca da imposição de medida de segurança detentiva ao inimputável psíquico, tem-se o art. 99 do referido código que, em sua rubrica lateral, estabelece como direito do internado o de ser recolhido a estabelecimento dotado de características hospitalares e de ser submetido a tratamento. 
$\mathrm{O}$ 'estabelecimento dotado de características hospitalares’ é o hospital de custódia e tratamento psiquiátrico, segundo previsão do art. 96, I, também do Código Penal', ou seja, é o local onde, segundo a lei penal, deve ser cumprida espécie de sanção penal, que é a medida de segurança detentiva.

Importa colacionar passagem da obra de Ibrahim $^{8(25)}$, reportando percepção de indivíduo internado no então ativo Manicômio Judiciário do Rio de Janeiro: "Que lugar é esse? ‘[...] Eu não sei se isso aqui é um hospital implantado numa cadeia, ou se é uma cadeia implantada num hospital"'.

Ou seja, o direito do internado, segundo previsão legal, é o de ser submetido a sanção penal que importa privação de sua liberdade, como forma de acesso ao tratamento médico a que tem direito, segundo previsão constitucional do art. 196 da Constituição Federal ${ }^{5}$, especificamente tratamento médico-psiquiátrico. A indagação que se impõe é: se cumprir sanção penal imposta é direito, qual seria, efetivamente, a sanção?

\section{Uma saída alternativa}

No contexto de vigência e aplicação do Código Penal', em conformidade com os princípios e as regras expostos nos dois primeiros capítulos deste trabalho, é publicada, em 09 de abril de 2001, a Lei ${ }^{\circ} 10.216^{2}$, que dispõe sobre a proteção e os direitos das pessoas portadoras de transtornos mentais e redireciona o modelo assistencial em saúde mental, conhecida como Lei da Reforma Psiquiátrica ou Lei Antimanicomial, estabelecendo novos paradigmas para os cuidados em saúde mental no Brasil, operando a chamada Reforma Psiquiátrica.

Apesar dos retrocessos políticos constatados nos últimos anos, a lei permanece vigente no momento de produzido este artigo.

A referida reforma deixa para trás o antigo modelo manicomial, cuja regra é a internação das pessoas acometidas de transtornos mentais em instituições totais, com características asilares. Pelo modelo manicomial, o atendimento às pessoas com transtornos mentais é centrado em hospitais psiquiátricos, tendo por objetivo o tratamento da doença mental, a busca da cura.

O novo modelo de cuidado em saúde mental, instituído pela Lei da Reforma Psiquiátrica, opera em sistema de rede de atendimento, a chamada Rede de Atenção Psicossocial (Raps), vinculada ao Sistema Único de Saúde e instituída pela Portaria MS no $3.088^{9}$, de 23 de dezembro de 2011. A Raps opera em base territorial, regionalizada e comunitária, com participação dos usuários e seus familiares e submetida a controle social por esses atores. Tal modelo de atendimento visa à promoção da saúde mental, por meio da socialização - adaptação dos indivíduos acometidos de transtorno mental ao e no meio social -, respeitando sua condição e buscando combater estigmas e preconceitos, por meio de atenção humanizada e centrada nas necessidades dos usuários.

Verifica-se, portanto, que não tem mais espaço para o modelo antigo, de tratamento asilar e segregacionista, que não se amolda aos objetivos e às diretrizes do modelo antimanicomial.

Igualmente, não tem mais lugar o modelo estabelecido no Código Penal Brasileiro' ${ }^{1}$ de resposta sancionatória ao agente inimputável psíquico que pratica injusto típico.

Considerando-se o arcabouço jurídico-legal brasileiro, verifica-se um cardápio de normas jurídicas, entre princípios e regras, disponível ao aplicador do direito para solucionar os casos a ele submetidos. Nesse contexto de diversidade legal, muitas vezes, verifica-se multiplicidade de normas regulando os mesmos casos ou as mesmas questões fáticas, cabendo ao jurista utilizar-se de mecanismos para eleger qual a norma aplicável entre as disponíveis. Tal fenômeno não é exclusivo do ordenamento jurídico brasileiro, podendo ocorrer, hipoteticamente, em qualquer sistema de normas.

Essa multiplicidade de normas regulando a mesma questão fática, supostamente vigentes no mesmo período de tempo, no mesmo sistema jurídico, caracteriza o fenômeno jurídico do conflito de normas, assim conceituado e classificado por Kelsen ${ }^{10}$ : 
Existe um conflito entre duas normas, se o que uma fixa como devido é incompatível com aquilo que a outra estabelece como devido e, portanto, o cumprimento ou aplicação de uma norma envolve, necessariamente ou possivelmente, a violação da outra. O conflito pode ser bilateral ou apenas unilateral. É bilateral se o cumprimento ou aplicação de cada uma das duas normas envolve, necessariamente ou possivelmente, uma violação da outra. É unilateral, se apenas o cumprimento ou aplicação de uma das duas envolve violação da outra. O conflito pode ser total ou parcial. É total se uma norma impõe uma conduta determinada, a outra proíbe justamente esta conduta (impõe a omissão da conduta). É parcial se o conteúdo de uma norma só em parte é diferente do conteúdo da outra norma10(157). [grifo do autor].

Com base nessa classificação de Kelsen ${ }^{10}$, verifica-se que existe conflito de normas entre o Código Penal ${ }^{1}$ e a Lei $\mathrm{n}^{0} 10.216 / 2001^{2}$ em relação às disposições acerca da imposição de medida de segurança ao inimputável psíquico e os novos paradigmas da Lei Antimanicomial. Tal conflito é bilateral, pois a aplicação de uma das normas necessariamente envolve violação da outra, e total, pois a Lei ${ }^{0} 10.216 / 2001^{2}$ veda condutas que os arts. 96 a 99 do Código Penal ${ }^{1}$ determinam. Por outro lado, se a comparação for realizada entre as normas da Lei da Reforma Psiquiátrica e a totalidade das disposições do Código Penal' , o conflito é parcial, por abranger apenas os referidos artigos.

No caso específico do presente estudo, verifica-se antinomia jurídica relativamente às disposições contidas nos arts. 96 a 99 do Código Penal ${ }^{\mathbf{1}}$ - que compõem o Título VI da Parte Geral e disciplinam a medida de segurança - e às disposições da Lei ${ }^{\circ} 10.216 / 2001^{2}$, que dispõe sobre a proteção e os direitos das pessoas portadoras de transtornos mentais e estabelece novos paradigmas para a assistência em saúde mental.

Nesse sentido, o Código Penal ${ }^{\mathbf{1}}$ estipula a obrigatoriedade de imposição de medida de segurança detentiva ao inimputável psíquico que pratica fato definido como crime, punível com pena privativa de liberdade de reclusão, conforme já demonstrado.

Por outro lado, a Lei da Reforma Psiquiátrica determina a adoção de práticas de socialização e inserção social das pessoas portadoras de transtorno mental, com sistema de atendimento por rede de serviços comunitários, conforme anteriormente explicitado, prevendo, em síntese:

- direitos específicos de que são titulares as pessoas acometidas de transtorno mental, entre os quais, o de receber tratamento humano e respeitoso durante o tratamento, com vistas à recuperação de sua saúde mental, pela inserção na família, no trabalho e na comunidade;

- a permanência do doente mental no convívio familiar e comunitário, vedando a hospitalização como regra, sendo esta permitida apenas quando os recursos extra-hospitalares se mostrarem insuficientes;

- em casos excepcionais, em que indicada a hospitalização do doente mental, a vedação de internação por prazo indeterminado;

- a vedação expressa de internação de pessoas com transtornos mentais em instituições asilares, nas quais são inacessíveis serviços multidisciplinares de assistência integral a tais indivíduos, incluindo serviços médicos, de assistência social, psicológicos, ocupacionais e de lazer por exemplo;

- diretrizes para desinstitucionalização de doentes mentais submetidos a longas internações psiquiátricas, estabelecendo providências a serem adotadas pelos Poderes Legislativo e Executivo;

- as espécies (excepcionais) de internação psiquiátrica de pessoas com transtornos mentais. 
Resta clara, portanto, a incompatibilidade das previsões do Código Penal quanto à obrigatoriedade de imposição de medida de segurança ao inimputável psíquico, critérios de aplicação, espécies de tal sanção penal e compulsoriedade de internação do doente mental, para tratamento, em ambiente asilar, em relação às disposições humanitárias, desinstitucionalizantes e socializantes da Lei $\mathrm{n}^{\mathrm{o}}$ $10.216 / 2001^{2}$.

Por outro lado, analisando-se o sentido do texto do $\subseteq 2^{\circ}$ do art. $2^{\circ}$ da Lei de Introdução às Normas do Direito Brasileiro" e o conteúdo do critério da especialidade, bem como sua técnica de aplicação, anteriormente exposta, verifica-se que, caso lei geral ou especial posterior estabeleça disposições compatíveis com as já existentes - sejam especiais ou gerais -, ambas as leis devem coexistir no ordenamento jurídico, uma vez que não há incompatibilidade entre elas. Contudo, caso lei geral ou especial nova estabeleça disposições incompatíveis com as já existentes - sejam especiais ou gerais -, a lei mais antiga necessariamente restará revogada.

\section{Considerações finais}

Concluída a análise do cenário protagonizado pelo sujeito portador de transtornos mentais que pratica fato típico e ilícito, verifica-se que a perspectiva deve ser inovadora, com aplicação da Lei Antimanicomial, e não do Código Penal, não mais se impondo medida de segurança ao inimputável psíquico que pratica fato típico e ilícito, e, sim, disponibilizando-lhe cuidado e atenção em saúde mental no contexto da rede de atendimento que a ele é disponibilizada a partir da entrada em vigor da Lei ${ }^{\circ}$ 10.216/2001 e seus consectários infralegais.

Acredita-se que a permanência da aplicação do Código Penal, apesar de tacitamente derrogado pela Lei da Reforma Psiquiátrica, com a consequente imposição de sanção penal a sujeito que não tem consciência da própria conduta - circunstância que flerta com a responsabilidade penal objetiva -, deve-se à tentativa de aplacar o estado de coisas no qual se encontra o Brasil - insegurança, violências institucionais, ausência de sentimento de pertencimento pelo indivíduo, desesperança. Assim, com a imposição de medida de segurança, é recebida pela sociedade uma resposta do Estado diante da prática de fato típico e ilícito, independentemente da consciência do sujeito praticante e do resultado efetivo da imposição da medida de segurança detentiva. Nesse sentido, a internação em Hospital de Custódia e Tratamento Psiquiátrico, que é, efetivamente, encarceramento humano, em nada contribui para construção e fortalecimento de laços sociais e afetivos do indivíduo internado; pelo contrário, priva-o de tratamento adequado, em meio aberto, na companhia de familiares e amigos e com vistas à sua adaptação social.

A visão não deve ser mais hospitalocêntrica e centrada na atuação médica, mas plúrima, multidisciplinar, com participação efetiva do próprio usuário dos serviços de saúde mental, de sua família e da comunidade.

A virada ética e ideológica representada pela Lei Antimanicomial tornou inequívoca a condição do inimputável psíquico, autor de fato típico e ilícito, de sujeito de direitos à promoção de sua saúde mental, à inclusão social, ao não encarceramento; e tais direitos devem ser respeitados.

Apesar disso, o que se verifica, na prática, são retrocessos no movimento antimanicomial em curso, cujo ápice foi a edição da Lei $\mathrm{n}^{0} 10.216 / 2001$ e que se encontra em xeque ante as normas infralegais que vêm, de forma antidemocrática, retirando-lhe aplicabilidade.

Nesse contexto, é medida imprescindível trazer ao centro do debate social as medidas que vêm sendo adotadas, nas diversas esferas de governo, visando ao enfraquecimento da luta antimanicomial como forma de resistência e alerta das consequências nefastas de postura punitivista, encarceradora, patologizante e tolhedora das liberdades e autonomia individuais. 


\section{Colaboradores}

Lopes AV (0000-0001-9097-4906)* contribuiu substancialmente para a elaboração do rascunho; para a concepção, o planejamento e para a análise dos dados. Schutz GE (00000002-1980-8558)* contribuiu significativamente para a revisão crítica do conteúdo e participou da aprovação da versão final do manuscrito.

\section{Referências}

1. Brasil. Decreto-lei no 2848 , de 7 de dezembro de 1940 [internet]. Código Penal. [acesso em $2018 \mathrm{dez} 8$ ]. Disponível em: http://www.planalto.gov.br/ccivil_03/ decreto-lei/del2848compilado.htm.

2. Brasil. Lei $n^{0} 10.216$, de 06 de abril de 2001. Dispõe sobre a proteção e os direitos das pessoas portadoras de transtornos mentais e redireciona o modelo assistencial em saúde mental [internet]. Diário Oficial da União. 7 Abr 1940. [acesso em 2019 jan 26]. Disponível em: http://www.planalto.gov.br/ccivil_03/leis/ leis_2001/110216.htm.

3. Masson C. Direito penal esquematizado: parte geral. São Paulo: Método; 2016.

4. Farias CC, Rosenvald N. Curso de Direito Civil: famílias. 8. ed. Salvador: JusPodivm; 2016.

5. Brasil. Constituição da República Federativa do Brasil [Internet]. Brasília, DF: Senado Federal; 1988. [acesso em 2018 set 15]. Disponível em: http://www.planalto.gov.br/ccivil_03/constituicao/constituicao.htm.

6. Carvalho S. Penas e medidas de segurança no direito penal brasileiro. 2. ed. São Paulo: Saraiva; 2015.

${ }^{*}$ Orcid (Open Researcher and Contributor ID).
7. Santos JC. Direito penal: parte geral. 8. ed. Florianópolis: Tirant lo Blanch; 2018. Revisada e Ampliada.
8. Ibrahim E. Manicômio judiciário: da memória interrompida ao silêncio da loucura. Curitiba: Appris; 2014.

9. Brasil. Ministério da Saúde. Biblioteca Virtual em Saúde [internet]. Portaria ${ }^{0} 3.088$, de 23 de dezembro de 2011. Institui a Rede de Atenção Psicossocial para pessoas com sofrimento ou transtorno mental e com necessidades decorrentes do uso de crack, álcool e outras drogas, no âmbito do Sistema Único de Saúde (SUS). Diário Oficial da União. 24 Dez 2011. [acesso em 2019 fev 2]. Disponível em: http://bvsms.saude. gov.br/bvs/saudelegis/gm/2011/prt3088_23_12_2011_ rep.html.

10. Kelsen $\mathrm{H}$. Teoria geral das normas = Allgemeine Theorie Der Normen. Porto Alegre: Sergio Antonio Fabris Editor; 1986.

11. Brasil. Decreto-lei ${ }^{\circ} 4.657$, de 4 de setembro de 1942 [internet]. Lei de Introdução às normas do Direito Brasileiro. Diário Oficial da União. 5 Set 1943. [acesso em 2019 jan 2]. Disponível em: http://www.planalto.gov.br/ccivil_03/decreto-lei/Del4657.htm.

Recebido em 09/09/2019

Aprovado em 05/11/2019

Conflito de interesses: inexistente

Suporte financeiro: não houve 